\title{
The Benefits of Translation: With a Special Reference to the Armenian Translation of Five Short Stories by W. Saroyan
}

\author{
Seda Melkumyan \\ MA student, Translation Studies, University of Isfahan, Iran \\ E-mail: Seda_mel@yahoo.com \\ Azizollah Dabaghi \\ Assistant Professor, TEFL, University of Isfahan, Iran \\ E-mail: azizollahd@hotmail.com
}

Received: May 22, 2011

Accepted: June 11, 2011

Published: October 1, 2011

doi:10.5539/ass.v7n10p128

URL: http://dx.doi.org/10.5539/ass.v7n10p128

\begin{abstract}
In the scope of Literary Translation, the present article focuses on the benefits of translation which is technically referred to as translation gain. Defined as "translator's technique used to compensate for translation loss" (Note 1), translation gain has scarcely been a subject of heated debates among the authorities in the field of Literary Translation. The data for the present study was collected from the Armenian translation of 5 short stories written by a famous Armenian-American writer W. Saroyan (1908-1981). One of the main objectives of the study is that it covers translations into a language of limited diffusion-Armenian. The results of the study will come to show that in the course of recreating the original, the translator may add values to it either because s/he grasped the author's thought rather better or by taking advantage of the target language's neater and/or richer linguistic resources.
\end{abstract}

Keywords: Translation gain, Literary translation, Short story, William Saroyan

\section{Introduction}

Translation is one of the world's oldest professions. As defines Shiyab (2006: 21); translation is as old as the history of universe. An inseparable part of this activity was and is literary translation. As defined by Levy (1963, pp 65-69 in Munday 2001, p 62) literary translation is a reproductive and creative labour with the goal of equivalent aesthetic effect. Throughout the history, translation of literary works has enriched and refined the national literary norms and styles of target languages; it has brought together great authors making their works universal. Translation of literary works has also contributed to the context of globalisation by allowing people from different backgrounds to read literature classics in their mother tongues. For this particular reason, the art of literary translation should be rewarded and praised. A key role in translation in general and in literary translation in particular is played by the translator-a person who makes a unique composition universal. There exist many possible metaphors describing translators; in one case they are 'bridge builders across the Space between source and target' (Bassnett: 10:1991), in another- 'travellers engaged in a journey from one source to another' (Cronin: 2000). In the metaphor of Green (2010:10) translators are 'puzzle-solvers' or 'musical arrangers' Despite the existing differences in its definitions, literary translators should undoubtedly possess certain profusion of qualities and fulfil a great amount of responsibilities.

\section{Background of the Study}

Language differences bring about a frequent problem of non-equivalence in the process of transfer from ST to TT. Terms like translation equivalence, adequacy, and mistranslation are much-used and sometimes even abused items in Translation Studies. Previous studies, that have touched upon the infidelity of translated text with its original one, innumerate a great number of points that may cause the lack of equivalence at the level of structure, semantic meaning, discourse features and effect whereas translation gain has been deficient of proper attention. Translation loss is contrasted by translation gain-a translation technique used to compensate for translation loss. 
The translator offsets an investable loss at one point in the text by adding a suitable element at another point, achieving a compensatory translation gain. (Hatim, Monday, 2004:31). Bassnett (1991:38) points out that "it is an indication of low status of translation that so much time should have been spent on discussing what is lost in the transfer of a text from SL to TL whilst ignoring what can also be gained, for the translator can at times enrich or clarify the SL text as a direct result of the translation process". In fact, Toury (1995:53) mentions that "the process by which a bilingual speaker may be said to gain recognition in his/her capacity as a translator has hardly been studied so far'. Despite the existing debates about the definition of the two notions of 'translation' and 'literary translation', there exist many instances where one may maintain the superiority of a translated version of a literary text over his original. Bassnett (1991:60) in her Translation Studies brings about the case of Wyatt's translation of Petrarch. She stresses the fact that Wyatt's English translation shows faithfulness not to individual words or sentence structures but to a notion of the meaning of the poem in its relationship to its reader. She stresses the point that Petrarch's poem is perceived as an artefact of a particular cultural system, for that reason, Bassnett concludes that the only faithful translation of Petrarch's poem can be to give it a similar function in the target cultural system. In another case, Newmark (1998:176) mentions Baudelaire's French translations of Edgar Alan Poe which are agreed to be superior to their originals. Another vivid example is represented by Eoyang (1999:306) in Translation of Poetry and Poetic Prose. He mentions that "speaking about Gregory Rabassa's English translation of "One Hundred Years of Solitude", the author himself, Gabriel García Marquez, insists that he prefers the English translation to the original". This leads Eoyang to conclude that Garcia Marquez "might admit that he loses something in the original". Lev Nikolayevich Tolstoy wrote on one occasion (Lenkov, 1977:227 cited in Friedberg, 1997:10) that the magic perfection of Pushkin's dramatic poem "The Gypsies" became apparent to him only upon reading the poem in French. A comparison of the original with the translation unexpectedly unfolded to him unnoticed aesthetic qualities of an overly familiar Russian text. The translation became the mirror which enabled Tolstoy to see those features of the original which he failed to notice earlier in the original.

The discussion of everlasting coexistence of the two notions of gain and loss in translation clearly has much room for further 'attacks' on the basics of literary translation. Whatever the disagreements in judging the value of the translations may be, one may well accept that every literary work is a unique creation which translation can never zero transformation, together with creating distortions, it is always adding values which make translation not so much as losing source elements but as changing them.

\subsection{Translation of Literary Work}

Literary translation is one of the four principal categories of translation. The others are interpreting, scientific and technical and commercial/ business translations. Translation of literary works is said to be an art in itself as it is concerned with conveying innumerable literary elements including word order, rhythm, structure, sound effect, tone, conciseness and various literary devices. Through such elements a literary text is able to perform multiple functions.

In order to unpack the differences between literary and general translation, one must turn to the basic differences between literary and non-literary texts. Newmark (1998:63) marks a broad distinction in regard to literary and non-literary texts, according to him, literary texts are allegorical and more or less express the moral comment or criticism of life. Instead, non-literary texts are distinguished by their facts, events and ideas, without connotations. Newmark (1998:102-103) suggests five main features that characterise a well-written literary language.

a) it is virtually figurative and allegorical

b) its sound is as important as its meaning -it is in the deepest sense, onomatopoeic

c) it follows the 'quick' rhythm of speech, which have to be rendered by the translator

d) it is concentrated, each word in indispensable

e) it is likely to have more polysemous words and collocations than denotative language

Hochel (1991:41-48) characterises a literary translation as a three-fold or three dimensional activity since it has to be translated or transferred

1. from one natural language to another

2. from one time (i.e. that of the creation of the original) into another (that of the creation of the translation)

3. from one space (cultural milieu) into another. 
According to him, what makes the literary work outstanding is its literary language, which should not be confused with 'the language of literature' understood as a secondary modelling system. Hochel defines literary language as 'the choice and frequency of means of natural or primary language'.

\title{
2.1.1 Translation of Short Stories
}

Short Story is a brief fictional prose narrative which is to be distinguished from longer, more expansive narrative forms narrative forms such as novel epic, saga and romance. The short story is usually concerned with a single effect conveyed in a single significant episode or scene. It involves a limited number of characters, sometimes only one (Merriam Webster's Encyclopaedia of Literature 1995:1028).

According to Newmark (1993:48-49), the short story is the second most intimate and personal form of writing in imaginative literature after poetry. He emphasises the essence of short story as compactness, simplicity, concentration and cohesion. He further distinguishes between the following significant features of short stories, which should be reproduced in translation,

1. Its structure. Opening and closing sentences and paragraphs are often mutually related as well as the title and its resolution.

2. Keywords or leitmotifs. These are often repeated words, phrases or images which indicate the theme.

3. Stylistic markers. These are author's typical words or structures which are also related to the theme.

4. Cultural and universal (encyclopaedic) references.

5. Cultural metaphors

6. Gender: tale or story, spoken or written mood.

7. Tradition. The story may be in line with an established tradition.

8. Collateral works.

9. Functional sentence perspective: the coherent and cohesive link of the sentence stress.

Newmark states that cultural and universal reference should be economically explained in terms of space. Tradition and collateral works are also under stress. Newmark states that the tradition of the source language must be preserved rather than adopted to a target language tradition in order to enrich its literature. As to the collateral work, Newmark assures that translators may gain in understanding one work of an author by reading his/her other works. The distinction between keywords and leitmotifs is presented in the following way:

"Leitmotifs are peculiar to short stories, characterising a character or a situation".

"Key-word is the word or phrase that typifies the writer rather than the peculiar text". (Newmark: 1988:171)

In translating these two features, Newmark attaches importance to the fact that leitmotifs should be appropriately foregrounded and repeated in the translation. Whereas key-words may more or less be reproduced by the translator owing to their strictly personal nature.

Not only is the translation of short stories delightful but it is also rewarding. The very shortness of the short story permits the comparative analysis of entire text, which is a formidable task for longer prose forms such as novel.

\section{Methodology and Procedures}

The data for the present study was collected by analysing the gained features, on the word and sentence level, resulted in the Armenian translation of 5 short stories by an American-Armenian writer William Saroyan. The stories under discussion are translated by the same translator- Khachik Hrachyan. The stories under study were:

\section{The Man with the Heart in the Highlands}

\section{Fu WhMUn Ltnithmed t}

\section{The Sunday Zeppelin}

\section{Wh}

\author{
3. The first Day of School
}

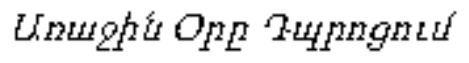




\section{Three, Four Shut the Door}

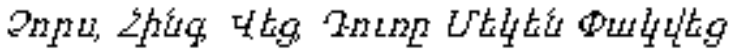

\section{The fifty-Yard Dash}

$$
\text { ל̧unclu Bupruming Чuqq }
$$

Saroyan (1908-1981) was a prolific writer of short stories and novels; his works are known for their free style and intensely expressed autobiographical elements. Both the historical period and the writer's life background have left an indelible mark on the content of his works.

The works under discussion were written and published in the period of $1935-1940$ in the years of the Great Depression $^{1}$ in the United States.

The fundamental reasons serving to account for the choice of the writer, the type of the literary fiction and the selection of the short stories are as follows.

1. The choice of the writer is conditioned by several factors. Saroyan is one of the most renowned Armenian writer in the Literature of Armenian Diaspora and the most famous and beloved writer among American-Armenian writers. In the history of literature, Saroyan belongs to the company of such writers as J.D. Salinger, F. Dostoevsky, H. Heine, A. C. Doyle, S. Plath, etc. Saroyan is a winner of the Pulitzer Prize (Note 2) and New York Drama Critics' Circle (Note 3).

2. The choice of the literary fiction is not arbitrary. Out of the existing specific features proscribed to short stories are their briefness, autobiographical or personal nature as well as unique style owing to the fact that authors often use symbols and recurring images to help convey the ideas. This can take the form of symbolism, personification, etc. If the briefness of the story may lead the translator into thinking that the translation may be accomplished in a flash, the process will surely prove that the shorter the work the more difficult it is to have an accurate translation since almost nothing can be deleted or omitted in a short narrative. The above mentioned features make the translation of short stories both challenging and rewarding.

3. It was central to the study to choose the short stories translated by the same translator. A preference was given to those stories which have always enjoyed popularity among the readers hence resulting in extensive translations. In its turn, the choice of the translator was made in compliance with the existing literary theories.

\subsection{Procedures}

In order to achieve the objective of the study the following steps have been taken:

1. The short stories by W. Saroyan were studied.

2. The five short stories to be analysed were chosen.

3. The translated stories were contrasted and compared with their original version.

4. The gained features in the translation version were identified, paired and listed with the corresponding original versions.

5. The translation strategies adopted by the translator were identified.

6. The biographies of both the author and the translator were studied using the encyclopaedic data and biographical notes.

The gained features in the study were identifies based on word and sentence levels. The sentences in the translation of which gain is observed were contrasted to their originals. For practical purposes, the back translation in English is provided.

The translation strategies that the translator has used for conveying the meaning of the original were identified using the Model of Local Translation Strategies suggested by Chesterman (1997:101-104).

\subsection{The Model of Analysis}

For analysing the translation strategies applied by Hrachyan for translating the five short stories by Saroyan, Chesterman's model of local translation strategies was used. Chesterman (1997) states that in its simplest form, the taxonomy of translation strategies could consist of a single category, i.e. Change something. What Chesterman means here is that after producing the first translation of a particular string of text the translator 
often feels that it is not sufficiently good for various reasons. The normal types of changes made by translators have to do with the words used, the structures in which they are used, or the textual context in which the words appear. Thus, Chesterman divides local translation strategies into semantic, syntactic and pragmatic strategies. The strategies on pragmatic level are wider entities, whereas semantic and syntactic strategies are more detailed. Syntactic strategies are those local strategies that change the grammatical structure of the TT in relation to the ST. In other words, syntactic strategies look at translation changes at the structural level - changes in phrase, clause or sentence structure, changes of word class, unit shifts etc. Since the present study focuses on the message and the way it changes in the process of translation and not on the structure of the sentence, syntactic strategies were considered not relevant for the study and hence were not applied in analysing the data. Instead, the study focuses on pragmatic and semantic strategies, which often show the translator's general strategy in transferring the intended meaning of the author. Each of these two strategies contains ten subcategories which, taking into account the object of the study, were cut down to total six - three semantic and three pragmatic strategies.

Semantic strategies:

1). Synonymy

2). Trope Change

3). Hyponymy

Pragmatic strategies:

1). Cultural Filtering

2). Explicitation

3). Addition

\section{Data analysis, Results and Discussion}

Out of the chosen five short stories 40 examples of gained features were extracted. The examples illustrate vividly the success of the translator in transferring the author's intended meaning into the TT language and culture. Three examples from each strategy were presented from different stories. For practical purpose, each example comes with its English back translation (BT).

\subsection{Classification of Armenian gained features according to their translation strategies}

1) Semantic strategy 1: Synonymy (Se1).

The translator selects a synonym or a near synonym that is not the obvious first literal synonym of the SL word or phrase. In other words, the translator decides to use a less expected synonymous word or phrase for the purpose of emphasis. This Strategy was the dominant strategy used in the translation of these short stories.

\section{Example 1: The man with the Heart in the Highlands}

ST: "Young man, could you get a glass of water for an old man whose heart is not here, but in the highlands."

"What highlands?" I said.

"Scotch highlands," said the old man, "could you?"

"Where is your mother?" I said.

"My mother is in Tulsa, Oklahoma", said the old man, "but her heart isn't".

"Where is her heart?", I said.

"In the Scotch Highland," said the old man. "I am very thirsty, young man."

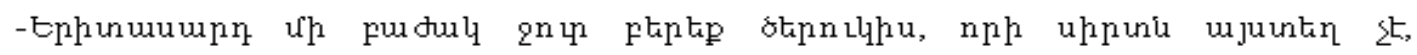
uJl lthiatipn Lu:

TT:

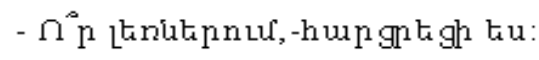




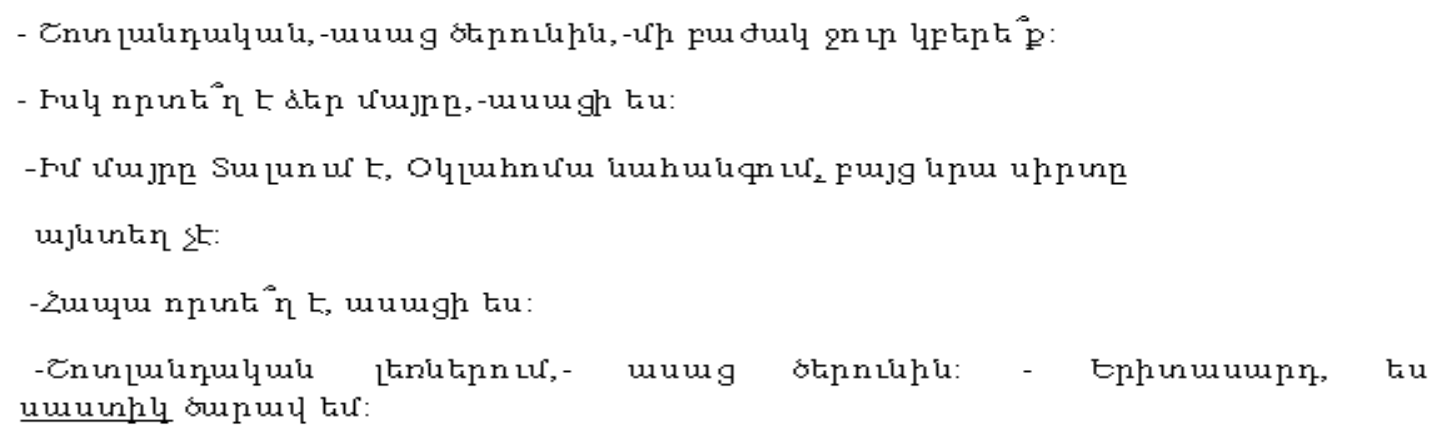

BT: "Young man, could you get a glass of water for an old man whose heart is not here, but in the highlands."

"What highlands?" I said.

"Scotch highlands," said the old man, "could you?"

"Where is your mother?" I said.

'My mother is in Tulsa, State Oklahoma, but her heart isn't.

"Where is her heart?", I said.

"In Schotch Highland," said the old man, "I am awfully thirsty, young man".

The word "very" has its direct equivalent in the Armenian language (quun), however, the translator decides to use a remote synonym to it (awfully). The use of the Synonymy strategy ( $\mathrm{Se} 1)$ is observed here which makes the translation more emphatic. The repetitive request of the old man to get a glass of water is faced with the boy's countless questions leaving the old man thirsty.

\section{Example 2: The Sunday Zeppelin}

ST: Mr Parker took a purse from his pocket, jingled some coins, picked out a quarter so all of us could see it, and dropped it among the other coins. He looked very noble... He looked as if he was going to save the whole world with that quarter.

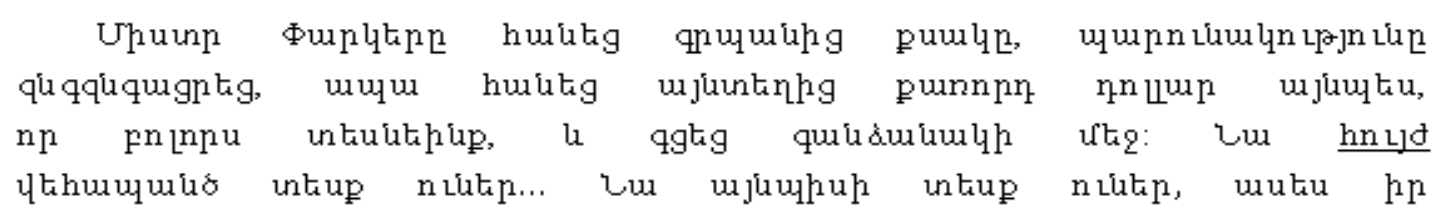

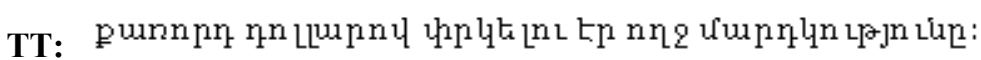

BT: Mr. Parker took a purse from his pocket, jingled the content of it, then picked out a quarter of a dollar so all of us could see it, and dropped it in the box. He looked highly noble... He looked as if he was going to save the whole mankind with that quarter.

The Synonymy strategy is observed by using the adverb "highly" instead of "very" the equivalent of which exist in the Armenian language (2uun) but was not preferred by the translator owing to the nature of the description given by the author.

\section{Example 3: The First Day of School}

ST: The school building was very ugly to her and to the boy. She didn't like the way it made her feel, and going up the steps with him, she wished he didn't have to go to school.

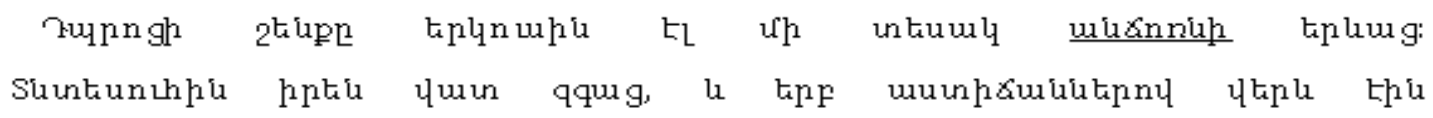

TT:

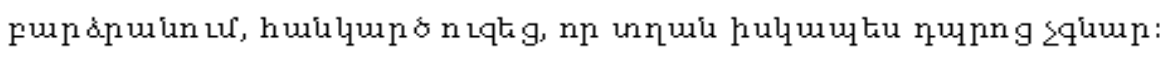


BT: The school building seemed very hideous to her. The housekeeper felt bad, and when they were going up the stairs, she wished he didn't have to go to school.

Despite the fact that the Armenian language has the direct equivalent of the word "ugly," the translator uses its less expected synonym "hideous". The choice of the translator is explained by the feeling that the building awakened in the housekeeper. Thus, the Synonymy Strategy (Se1) is used.

\section{2) Semantic strategy 2: Trope Change (Se2)}

The term trope is the formal name for a figure of speech. The trope change strategy has four forms:

A. ST trope A $\Rightarrow$ TT trope $A(\operatorname{Se} 2 A)$

An ST trope is retained as a trope in TT. In this case, the TT trope can be i) semantically identical, ii) semantically related, or iii) not semantically related but still the same type of trope as the ST trope.

\section{B. ST trope A $=>$ TT trope B (Se2B)}

The figurativeness is retained but the type of the trope changes (e.g. a ST metaphor is translated as a pun in TT).

C. ST trope A $\Rightarrow$ TT trope $\emptyset(\mathrm{Se2C})$

The trope is dropped in translation.

D. ST trope $\varnothing=>$ TT trope A (Se2D)

There is no trope in the ST but one is created in the TT.

\section{Example 1: The man with the heart in the highlands}

ST: "Get the old gentlemen some water," said my father. "God damn it, don't stay there like a dummy."

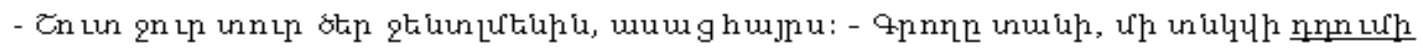

TT: Lưư:

BT: "Get the old gentlemen some water quickly," said my father. "Damn it, don't stand like a pumpkin.",

In this example the phrase like a dummy was translated like a pumpkin. The reason, researcher believes this to be a translation gain is that one of the meanings that the word pumpkin conveys in Armenian is a dolt person, which is also one of the meanings of the word dummy in NAmE. Besides, both phrases are similes in their original languages, hence, the Trope change strategy ( $\mathrm{Se} 2)$ is observed. In translation the trope was retained - although not semantically identical but still the same trope (simile).

\section{Example 2: The Sunday Zeppelin}

ST: "'Let me go up in the zeppelin with you, Luke."

"No," Luke said.

I didn't cry, but I felt sad. Then Luke got me sore.

"You like Alice Small,", he said.

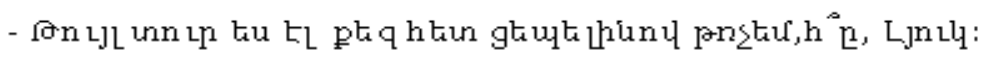

-Qt.-uuuug Ljn LlL:

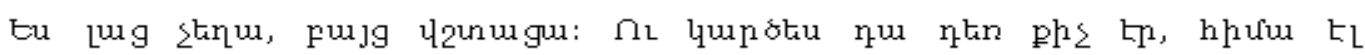
L.jn Llp ununhu nhupuul:

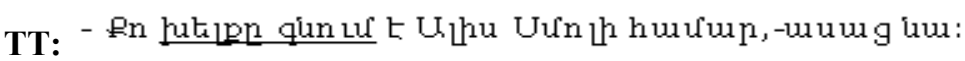

BT: "Let me fly with you in the zeppelin too, Luke.

"No", Luke said.

I didn't cry, but I got sad. And as if it was not enough, now Luke touched me on the raw.

"Your mind goes for Alice Small," he said.

In this example 2 strategies of Trope change (Se2D) were applied. Both belong to the D type of Trope change. The sentence "Luke got me sore" is translated into Armenian as "Luke touched me on the raw", here the Armenian translator has created a dead metaphor in the translation, which didn't exist in the original. In this way, the boy's feelings are expressed deeper than in the original. The Armenian metaphor "one's mind goes for smb" 
mean "'to be crazy about smb," Instead of "You like Alice Small,' is translated as "You are crazy about Alice Small'. Since the Armenian equivalent is a metaphor the following example is also a result of a Trope change, D type.

\section{Example 3: Three, Four, Shut the Door}

ST: Everybody in town saw the old yellow house burn down.

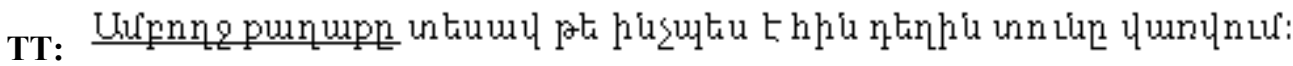

BT: The whole town saw the old yellow house burn down.

In the translation of this example synecdoche is observed which doesn't exist in the original version of the text. Here "everybody in town" has been translated into Armenian as "the whole town." This is a vivid example of synecdoche, since a general class of thing is used to refer to a smaller, more specific class. Thus, the strategy of D type of Trope Change has been used.

\section{2) Semantic Strategy 3: Hyponymy (Se3)}

Hyponymy is one member of a larger category (e.g. dog is a hyponym in relation to animal). Only two examples were extracted where this strategy was use.

\section{Example 1: The Fifty-yard Dash}

ST: She would sleep a little more, weaken and shout that there were once three sons of a king: one was wise like his father: the other was crazy about girls; and the third had less brains than a bird.

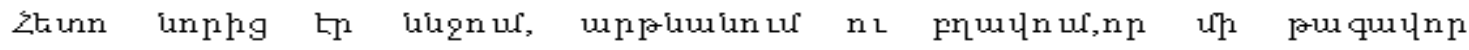

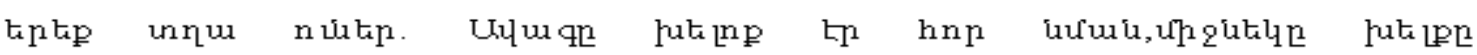

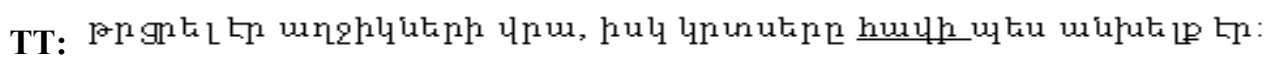

BT: Then she would sleep again, awake and shout that there was a king who had three sons; the elder son was wise like his father, the middle son was crazy about girls and the youngest was as silly as a hen.

The Armenian translation uses the word hen instead of bird; hen is one member of a larger category of birds. Hence, the Hyponymy Strategy is applied. By using this strategy the translator has been faithful in transferring the meaning. Since, hen in Armenia is associated with "brainless" animals.

Example 2: Three, Four, Shut the Door

ST: "Nobody in this whole country is going to lay a finger on this nigger. Not while I'm Sheriff, they ain't."

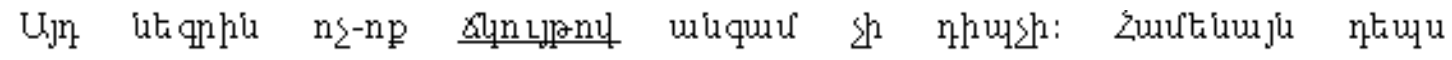

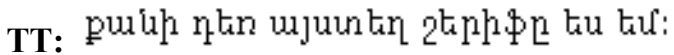

BT: Nobody is going to touch that nigger with the little finger. Not while I am the Sheriff here.

Little finger is one of five fingers; hence it is one member of a larger category of fingers. In Armenian both forms are applicable, but for the purpose of emphasis, the translator has used "'little finger", in order to emphasise how much the sheriff was concerned about defending the nigger child.

\section{3) Pragmatic Strategy 1: Cultural Filtering (Pr1)}

Cultural filtering is often used when translating culture-bound items. This strategy includes all kind of domestication of the text into target culture in a way that it fits into the world picture of the target culture and conforms to its norms.

\section{Example 1: The First Day of School}

ST: Jim said, What comes after twenty-nine?

Thirty, said Amy.

Your face is dirty, he said. 
Spứ uuug.

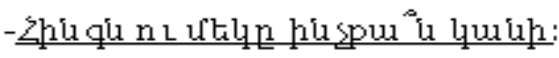

- uth g:

TT: - tptupn un up pultig:

BT: Jim said, "what makes five plus one?"

"Six".

"Your face is covered with soot.",

In this example, Jim, a six-year old boy, makes jokes with Amy learnt earlier in the school. The jokes are culture-bound which presupposed a target culture-centred translation. Not only has the Armenian translator succeeded to transfer the joke in the target culture, but he has also found an example which is semantically related to the ST one.

\section{Example 2: The First Day of School}

ST: He said, "Once there was a hill. On the hill there was a mill. Under the mill there was a walk. Under the walk there was a key. What is it?"

"I don't know, his father said. What is it?"

"Milwaukee," said the boy.

TT:

Lum unumg.

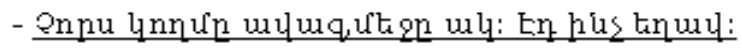

- Pqhuntu, -uuughujpL,-F is E:

- Lulu qualy, -uxuug un rui í:

BT: He said, "A wheel in the middle, and sand all four sides. What's that?

"I don't know", said the father, "what's that?"

"Bandit ".

In order to translate a riddle which is highly culture-bound, the translator creates a riddle in the target culture which is semantically related to the one in the source culture. As the word " "Milwaukee" comprises elements from the riddle told by the boy, the Armenian word for bandit ( riddle created by the translator. The solution given to the translation problem is proven to be successful.

\section{Example 3: Three, Four, Shut the door}

ST: "When he closed the door of the parlor, the room where the pianola was, he said, Three, four, shut the door."

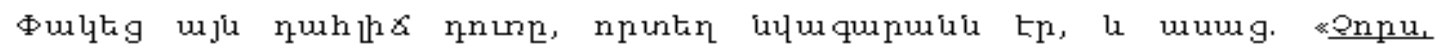

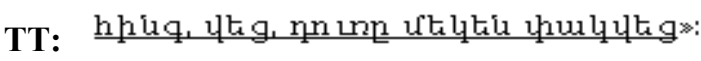

BT: "[He] closed the door of the hall, where the pianola was, and said, "Four, five, six, the door suddenly closed".

The Oxford Dictionary of Nursery Rhymes (1997:333-4) reveals that the underlined phrase is an allusion to a popular English language counting-out rhyme which goes as follows:

One, two,

Buckle my shoe;

Three, four, 
Shut the door...

In order to translate the rhyme into another culture, the translator has found a counting-out rhyme in the target culture, but still kept the meaning of the source culture rhyme. The Armenian rhyme goes like this:

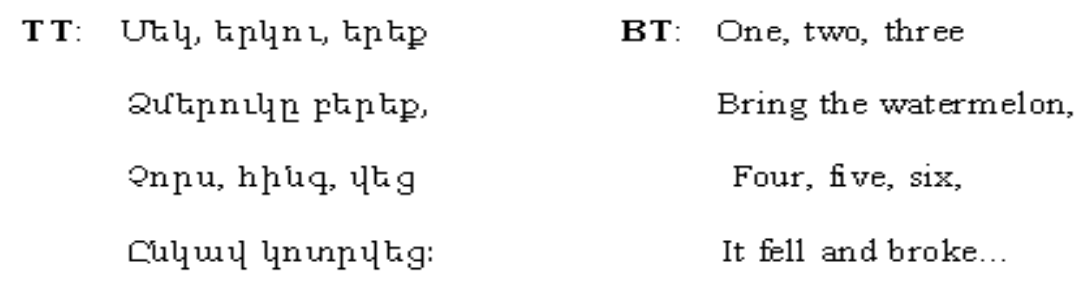

The translator has chosen the second part of the Armenian rhyme for the translation in order to match the rhyme. Not only is it an allusion to a counting-out rhyme in Armenian but it also semantically matches the massage of the source culture in the target one.

\section{5) Pragmatic Strategy 2: Explicitation (Pr2)}

This is a strategy that makes the target text more explicit by adding information that could in principal be deduced from the ST.

\section{Example: 1.}

ST: "Where is your mother's mother? 'I said.

"She is up in Vermont, in a little town called White River, but her heart isn't," said the old man.

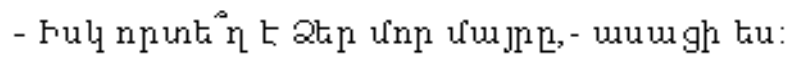

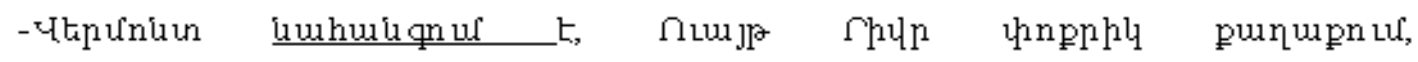

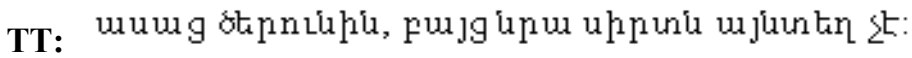

BT: "Where is your mother's mother?" I said.

"She is in the State of Vermont, in a little town called White River, but her heart isn't there".

If the native reader doesn't need to be reminded that Vermont is a state in the United States, the target reader needs to be informed about it. For that particular reason, the translator has added the word "state" in the TT.

\section{Example 2: Sunday Zeppelin}

ST: Mr. Parker took a purse from his pocket, jingled some coins, picked out a quarter so all of us could see it, and dropped it among the other coins. He looked very noble... He looked as if he was going to save the whole world with that quarter.

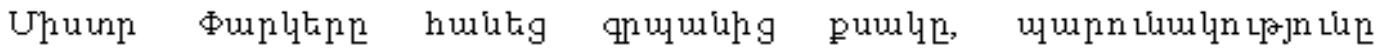

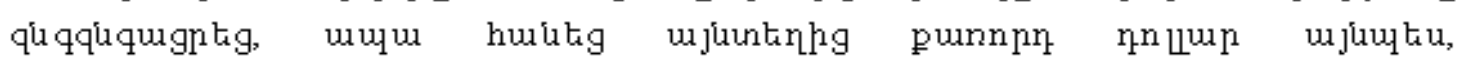

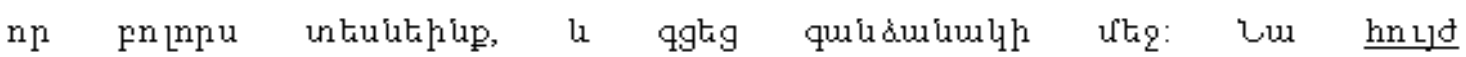

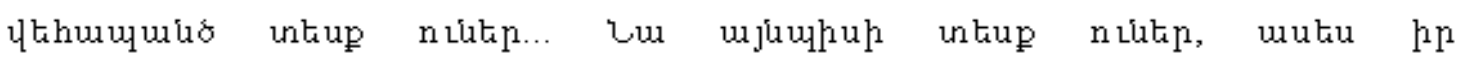

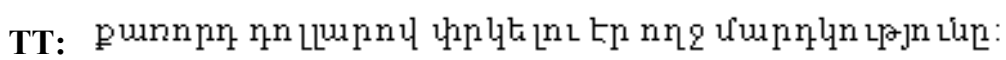

BT: Mr. Parker took a purse from his pocket, jingled the content of it, then picked out a quarter of a dollar so all of us could see it, and dropped it in the box. He looked highly noble... He looked as if he was going to save the whole mankind with that quarter.

If the ST reader doesn't need to be told that the word "quarter" is referred to the quarter of a dollar, the TT reader must be informed. Here the word "dollar" is added in the translation making it explicit to the TT readers.

\section{Example 3: The First Day of School}

ST: In the morning he asked his father for a nickel.

"What do you want a nickel for?" his father said.

"Gum," he said. 


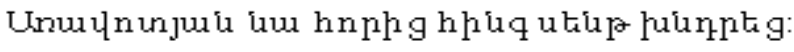

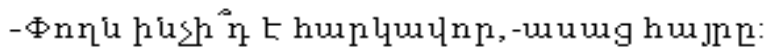

TT: - Oứnip hudup, -uuug unnuix:

BT: In the morning he asked his father for five cents.

' 'What do you want money for?', his father said.

"For gum,' he said.

While the meaning of the word nickel is clear to the source culture readers, it definitely requires explanation in the target culture. Each nickel equals fifty cents, which is used in the Armenian translation making it more explicit for the target culture readers. Hence, the Explicitation strategy ( $\mathrm{Pr} 2)$ is applied.

\section{6) Pragmatic Strategy 6: Addition (Pr6)}

By using this strategy, the translator is adding new information-word or phrase, in order to make the text serve its purpose better.

\section{Example 1: The Sunday Zeppelin}

ST: So we got a copy each of the Saturday Evening Post and started looking at the pictures. Luke wouldn't talk to me.

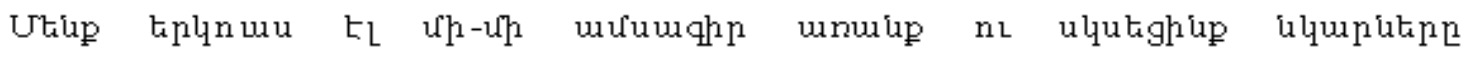

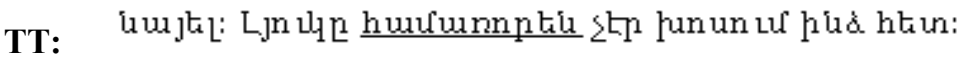

BT: We both got a copy each of the Saturday Evening Post and started looking at the pictures. Luke obstinately didn't talk to me.

In this example the Addition strategy (Pr3) is observed. Since the Armenian word for wouldn't doesn't possess the same meaning as the English one, the translator has added an adverb, obstinately, to better express that Luke was not going to speak with Mark.

\section{Example 2: The Fifty-Yard Dash}

ST: Johnny was a nigger who was almost white. Nobody liked Johnny. His own brothers didn't like him.

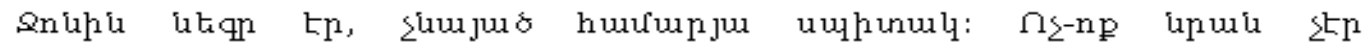

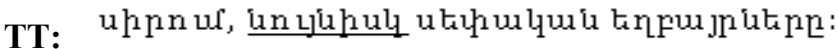

BT: Johnny was a nigger who was almost white. Nobody liked him; even his own brothers didn't like him.

Here the word "even" is added in the Armenian translation for the purpose of emphasising that even Johnny's brothers didn't like him.

\section{Example 3: The Man with the Heart in the Highlands}

ST: "Good afternoon", said my father. "Won't you come in for a little rest? We should be honoured to have you at our table for a bit of lunch.",

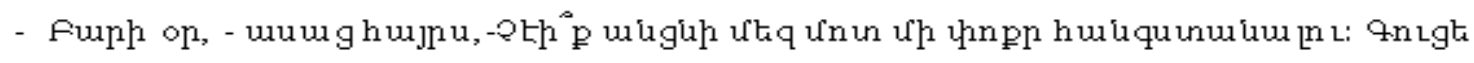

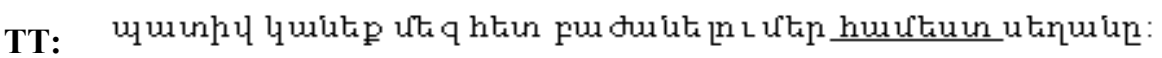

BT: “Good afternoon', said my father. 'Won't you come in for a little rest? Would you do us the honour of sharing our humble table?",

The word humble is added by the Armenian translator as an adjective of table, which shows the sincerity and simplicity of the character, as well as the poverty in which the characters were living. Hence, the Addition strategy (Pr3) is observed.

\subsection{Results of Data Analysis}

The researcher has counted the frequency of the strategies applied by the translator for translating all five short stories which have resulted in translation gain. The frequency of the strategies is presented in descending order. 


\section{Insert Table 1 Here}

\section{Conclusion}

The Synonymy strategy (Se1) proves to be dominated among the strategies applied by the translator for obtaining gain in translation process. Due to the subject's innovative nature, the analysis was done on 40 examples only. Another reason serving to account for the small number of the examples is that the research focuses the translation of short stories, which by definition are concise fictional texts. What the researcher hold firm is that each translation is the recreation of the original and in the course of recreating the original, the translator may add values to it either because s/he grasped the author's thought rather better or by taking advantage of the target language's neater and/or richer linguistic resources.

\section{References}

Armenian-English Dictionary. (2006). Yerevan, Macmillan Armenia.

Bassnett, S. (1991). Translation Studies. London: Routledge.

Chesterman, A. (1997). Memes of Translation. Amsterdam and Philadelphia, Benjamins.

Cronin, M. (2000). Across the Lines: travel, language, translation. Cork University Press.

English-Armenian Dictionary. (2007). Yerevan, Macmillan Armenia.

Eoyang, E. (1999). I lost something in the original. Translation as enhancement. In S. Allén, (Ed.) Translation of poetry and poetic prose: proceedings of Nobel Symposium 110 (p. 296). New Jersey: World Scientific Publishing Co. Pte. Ltd.

Friedberg, M. (1997). Literary translation in Russia: a cultural history. Pennsylvania: The Pennsylvania State University Press.

Green, G.M. (2010). Thinking through translation, Athens (USA). University of Georgia Press.

Hochel, B. (1991). The Cross temporal and cross-spatial factors and the translation of literary language in M. K. van Leuven-Zwart \& T. Naaijkeen (Eds.), Translation studies: the state of the art: proceedings of the First James S. Holmes Symposium on Translation Studies. Amsterdam: Rodopi.

Lee, L., \& Gifford, B. (1998). Saroyan: a biography. Barkeley/Los Angeles/ London: University of California Press.

Merriam Webster's Encyclopaedia of Literature. (1995). USA: Merriam-Webster, Inc.

Munday, J. \& Hatim, B. (2004). Translation: An Advance Resource Book. USA and Canada, Rutledge.

Newmark, P. (1988). A Textbook of Translation. Hertfordshire, Prentice Hall International.

Newmark, P. (1998). More paragraphs on translation. Clevedon, The Cromwell Press.

Saroyan, W. (1937). Little Children. London, Faber and Faber limited.

Saroyan, W. (1940). My Name is Aram. New York, Harcourt.

Saroyan, W. (1986). Entir Yerker: 4 Hatorov. Yerevan, Sovetakan Grogh.

Saroyan, W. (1994). Fresno Stories. New York, New Directions Publishing Corporation.

Shiyab, S.M. (2006). A textbook of translation: theoretical and practical implications. Antwerp, Garant Publishers.

The Oxford Dictionary of Nursery Rhymes. (1997). Opie I. Opie, P.,Oxford, Oxford University Press.

Toury, G. (1995). Descriptive translation studies and beyond, USA and The Netherlands, John Benjamins publishing.

\section{Notes}

Note 1. The Great Depression was a severe worldwide economic depression in the decade preceding World War II. The depression originated in the U.S., starting with the fall in stock prices that began around September 4, 1929 and became worldwide news with the stock market crash of October 29, 1929

Note 2. The Pulitzer Prize is a U.S. award for achievements in newspaper and online journalism, literature and musical composition. It was established by American publisher Joseph Pulitzer and is administered by Columbia University in New York City. 
Note 3. The New York Drama Critics' Circle is made up of 24 drama critics from daily newspapers, magazines and wire services based in the New York City metropolitan area. The organization was founded in 1935 at the Algonquin Hotel.

Table 1. Frequency and Percentage of Applied Translation Strategies

\begin{tabular}{|l|l|l|}
\hline Translation Strategy & Frequency & Percentage \\
\hline$(\mathrm{Se} 1)$ & 14 & $35 \%$ \\
\hline$(\mathrm{Se} 2)$ & 10 & $25 \%$ \\
\hline$(\operatorname{Pr} 3)$ & 7 & $18 \%$ \\
\hline$(\operatorname{Pr} 2)$ & 4 & $10 \%$ \\
\hline$(\operatorname{Pr} 1)$ & 3 & $8 \%$ \\
\hline$(\mathrm{Se} 3)$ & 2 & $5 \%$ \\
\hline Total & 40 & $100 \%$ \\
\hline
\end{tabular}

